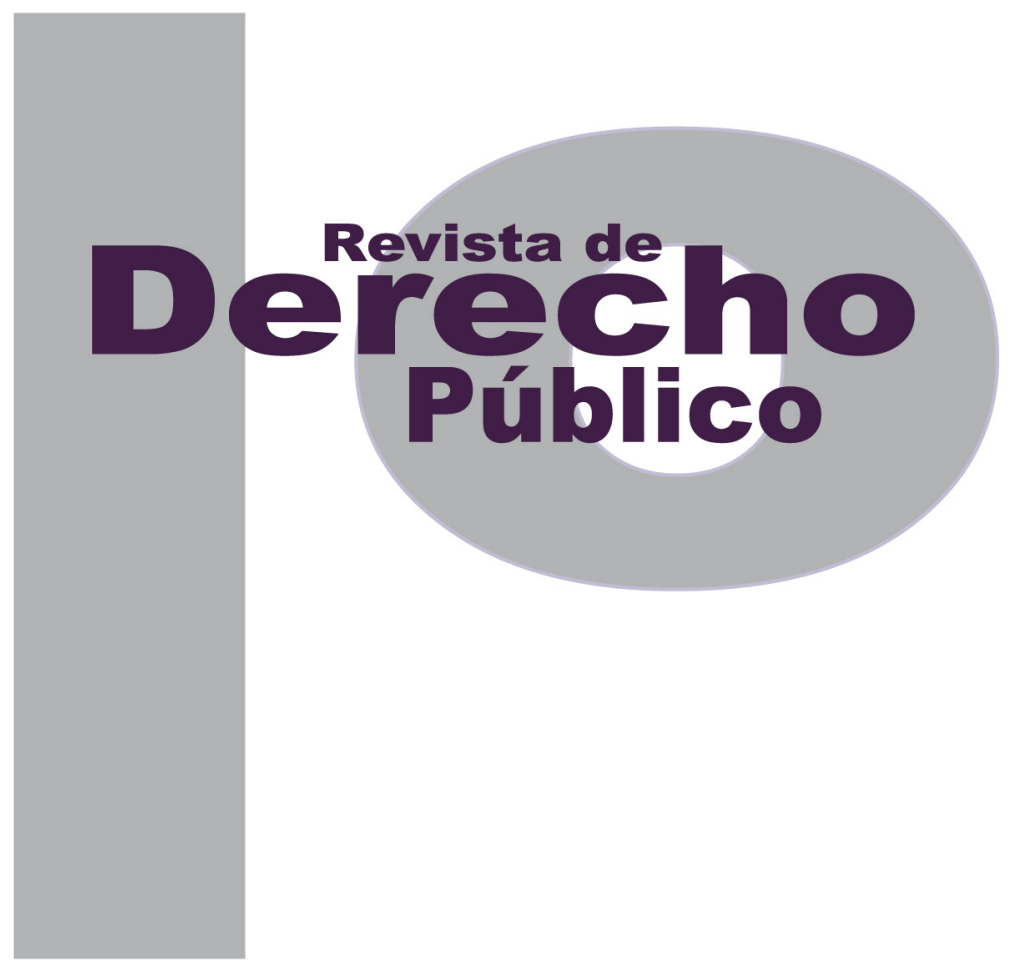

\title{
LA DIALÉCTICA ENTRE EL BLOQUE DE CONSTITUCIONALIDAD Y EL BLOQUE DE CONVENCIONALIDAD EN EL SISTEMA INTERAMERICANO DE DERECHOS HUMANOS
}

DAVID ANDRÉS MURILLO CRUZ

\section{Artículo de reflexión}

DOI: http://dx.doi.org/10.15425/redepub.36.2016.08

Universidad de los Andes

Facultad de Derecho

Rev. derecho publico No. 36

enero - junio de 2016. e-ISSN 1909-7778 


\title{
La dialéctica entre el bloque de constitucionalidad y el bloque de convencionalidad en el Sis- tema Interamericano de Derechos Humanos
}

\section{Resumen}

En este artículo, haciendo uso del método dialéctico, se tiene como objetivo principal describir el fenómeno conceptual del bloque de convencionalidad y su relación con el bloque de constitucionalidad al interior del Sistema Interamericano de Derechos Humanos. Esto, con el ánimo de precisar los elementos que lo componen y el modo como los jueces internos e internacionales deben aplicarlo. Así como de exponer, a manera de síntesis, el concepto de corpus juris común interamericano formado a través del pluralismo jurídico, en el que como tal no existe jerarquía normativa sino prevalencia de normas en casos concretos, en aplicación del principio pro homine.

Palabras clave: bloque de convencionalidad, bloque de constitucionalidad, control de convencionalidad, control de constitucionalidad, pluralismo jurídico, monismo, dualismo, derechos humanos, principio pro homine.

\section{The dialectics between the bloc of constitutionality and the bloc of conventionality in the Inter-American Human Rights System}

\begin{abstract}
This paper--based on the dialectical method--describes the bloc of conventionality and its relationship to the bloc of constitutionality in the Inter-American Human Rights System. It aims to provide a rigorous account of the elements that compose it and the way in which national and international judges have to apply it. It also lays out the Inter-American concept of corpus iuris formed through legal pluralism, which has no hierarchy of rules but rather prevalence of them in concrete cases given the application of the pro homine principle.

Key words: Bloc of conventionality; bloc of constitutionality; conventionality control; judicial review; legal pluralism; monism; dualism; human rights; pro homine principle.

\section{A dialética entre o Bloco de Constitucionalidade e o Bloco de Convencionalidade no Sistema Interamericano de Direitos Humanos}

\section{Resumo}

Neste artigo, fazendo uso do método dialético, se tem como principal objetivo descrever o fenômeno conceitual do bloco de convencionalidade e sua relação com o bloco de constitucionalidade ao interior do Sistema Interamericano de Direitos Humanos. Isto, com o ânimo de precisar os elementos que o compõem e o modo como os juízes internos e internacionais devem aplicá-lo. Assim como de expor, resumidamente, o conceito de corpus juris comum interamericano formado através do pluralismo jurídico, no que como tal não existe hierarquia normativa senão prevalência de normas em casos concretos, em aplicação do princípio pro homine.

Palavras-chave: bloco de convencionalidade, bloco de constitucionalidade, controle de convencionalidade, controle de constitucionalidade, pluralismo jurídico, monismo, dualismo, direitos humanos, princípio pro homine. 


\title{
La dialéctica entre el bloque de constitucionalidad y el bloque de convencionalidad en el Sistema Interamericano de Derechos Humanos*
}

\author{
DAVID ANDRÉS MURILLO CRUZ**
}

\begin{abstract}
SUMARIO
Introducción - I. LA TESIS DEL BLOQUE DE CONSTITUCIONALIDAD - A. De lo stricto sensu a lo lato sensu - B. De lo nominado a lo innominado - II. EL BLOQUE DE CONVENCIONALIDAD ¿LA ANTÍTESIS? - III. LA SÍNTESIS DEL CORPUS JURIS COMÚN INTERAMERICANO - IV. CONCLUSIONES - Referencias.
\end{abstract}

* Cómo citar este artículo: Murillo Cruz, D. A. (Junio, 2016). La dialéctica entre el bloque de constitucionalidad y el bloque de convencionalidad en el Sistema Interamericano de Derechos Humanos. Revista de Derecho Público, (36). Universidad de los Andes (Colombia). http://dx.doi.org/10.15425/redepub.36.2016.08

** Abogado de la Universidad Libre, máster en Derecho Internacional y doctorando en Derecho de la Universidad de Bordeaux (Francia). Docente honorífico de la Universidad Nacional Autónoma de México (UNAM) y docente de Derecho Público de la Universidad Libre. Correo: davidamurillo@hotmail.com 
Introducción

La tesis del bloque de constitucionalidad surge en el dinámico debate de la "constitucionalización" del derecho interno. Debate que tuvo su mayor suceso en el contexto de la formación de la comunidad europea (Cottier y Hertig, 2003), y que en la actualidad es de gran relevancia, debido a la requerida humanización del derecho estatal y a la necesidad de tomar "Ios derechos en serio" (Dworkin, 2012, p. 276). Sin embargo, es preciso aclarar que a pesar de su trayectoria histórica y de su desarrollo doctrinal, el término constitucionalización es aún demasiado ambiguo (Walter, 2007), pues se ha empleado en el derecho estatal para hablar de los efectos del derecho constitucional sobre las normas inferiores; en el derecho comunitario para transformar los tratados constitutivos en normas constitucionales; $y$ en el orden internacional para describir cómo la Carta de las Naciones Unidas se ha transformado en la constitución de la sociedad internacional (Walter, 2007).

Empero, a pesar de su ambigüedad el término constitucionalización se entenderá, para los efectos de este artículo, como la evolución del derecho interno, esto es, el proceso a través del cual se pasa de un estado de imperfección a un estado de claridad normativa, gracias a la existencia de un bloque de normas de carácter superior que se define de manera estricta o amplia, y que en su amplitud comienza a articularse con el nuevo fenómeno conceptual del bloque de convencionalidad.
Debe recordarse que la noción de bloque de constitucionalidad tuvo sus orígenes en la discusión sobre el potencial rango constitucional de algunas normas en el derecho interno, entre ellas, las contenidas en los instrumentos de derecho internacional (Góngora, 2011). Y que por medio de dicha discusión ciertas normas adquirieron en el derecho interno una importancia superior, al punto de constituir la esencia del sistema jurídico nacional y de convertirse en la bitácora del actuar tanto de autoridades públicas como de particulares.

Si bien el bloque de constitucionalidad ha tenido un conocido desarrollo de apertura al derecho internacional, es menester afirmar que su protección no se ha limitado a lo que estrictamente se encuentra escrito en los textos constitucionales o en los instrumentos internacionales. En realidad, en su aventura por proteger los derechos de las personas, se ha adentrado -gracias a la labor interpretativa de los jueces- en la identificación de nuevos derechos, que si bien no están previstos en los cánones normativos positivizados, no dejan por ello de pertenecer a la naturaleza del ser humano.

Un fenómeno similar se presenta en "el derecho internacional de los derechos humanos [que al ofrecer] un ambiente particularmente fértil al diálogo de jueces" (Hennebel, 2007, p. 31), ha permitido la identificación de un bloque normativo convencional, que además de constituir el horizonte jurídico de los jueces internacionales de derechos humanos, también se convierte en parámetro obligado de control para los jueces nacionales. 
El sistema interamericano es la ilustración más adecuada de esto, pues siendo en la actualidad el sistema regional con mayor impacto en la evolución de los derechos humanos, es también el más apropiado para determinar cuáles son los elementos que componen el "bloque de convencionalidad" (Ferrer, 2011, p. 532). Sobre todo, si se toma en cuenta, tal como lo viene considerando desde hace algunos años la doctrina en Europa, que "la Corte de San José se impone en efecto como una verdadera corte regional que sobrepasa ampliamente el rol de órgano de control de la Convención Americana de Derechos Humanos" (Hennebel, 2007, p. 55).

No obstante, y a pesar de las precisiones otorgadas por la Corte Interamericana de Derechos Humanos (Corte IDH), existen dudas sobre la relación operacional entre el bloque de constitucionalidad y el bloque de convencionalidad; sobre la primacía del uno sobre el otro y la manera en que estos deben ser aplicados por los jueces. Dudas que se han aclarado gracias al pluralismo jurídico y a la aplicación del principio pro homine, permitiendo que la discusión formal de jerarquía normativa se transforme en una cuestión sustancial de humanización del derecho y de protección reforzada del ser humano por medio del concepto de corpus juris común interamericano.

\section{LA TESIS DEL BLOQUE DE CONSTITUCIONALIDAD}

\section{A. De lo stricto sensu a lo lato sensu}

En la doctrina occidental se ha considerado como padre del concepto de bloque de constitucionalidad a Louis Favoreu (1975, pp. 3348). ${ }^{1}$ Bien podría esto ser admitido si se obvia que en el análisis histórico de dicha doctrina, la expresión bloque de constitucionalidad fue utilizada tiempo atrás por Émeri y Serin (1970, p. 678), en su crónica sobre la decisión del Consejo Constitucional francés del 21 de noviembre de 1969, relativa a las modificaciones aportadas al reglamento de la Asamblea $\mathrm{Na}$ cional de dicho país (Denizeau, 1997). Lo que sí se admite, es que Favoreu se convirtió en el padre adoptivo de la expresión, al determinar su contenido inicial.

En efecto, Favoreu al analizar los elementos que eran tomados en cuenta por el Consejo Constitucional francés al momento de realizar el control de constitucionalidad concluyó, que para este organismo judicial, la noción de Constitución había sido dotada de "una definición extensiva ya que en relación con las leyes esta noción recubre el texto constitucional, el preámbulo y todos los principios provenientes de los textos referidos por este, los tratados

1. Esto tras el análisis de las decisiones del Consejo Constitucional francés: 70-39 DC, del 19 de junio de 1970; $71-44$ DC, del 16 de julio de 1971; y 73-51 DC, del 27 de diciembre de 1973. 
o acuerdos, las ordenanzas y las leyes orgánicas" (1975, pp. 34 y 40). Para él, la constitucionalidad, a diferencia de lo que pensaba Charles Eisenmann (1928), no era la conformidad a una norma expresa de la Constitución, sino un proceso complejo que ya no consistía únicamente en analizar

la conformidad con textos expresos pero incluidos en textos exteriores al de la Constitución; sino sobre todo en el hecho de que la conformidad es verificada en relación con los principios fundamentales o generales que define el propio juez constitucional a partir de los textos de donde ellos emanan. (Favoreu, 1975, p. 40).

De esta manera, resulta para Favoreu (1975) que la conformidad normativa se aprecia en relación con la Constitución en stricto sensu,

pero también con el preámbulo (...) y más precisamente con la Declaración de los derechos [del hombre y el ciudadano] de 1789, con los principios fundamentales reconocidos por las leyes de la República, y el preámbulo de la Constitución [francesa] de 1946. (P. 38).

Gracias a esta noción, los tribunales constitucionales del mundo desarrollaron y enriquecieron el concepto de bloque de constitucionalidad, adaptándolo "como mecanismo para el reconocimiento de rango constitucional a los tratados de derechos humanos" (Góngora, 2014, p. 302), tal como lo han hecho en su gran mayoría los tribunales constitucionales latinoamericanos (Góngora, 2011). Pues:
Mientras que en Europa el concepto de bloque se refiere primordialmente a un conjunto de normas de origen nacional usadas como parámetro en el control de constitucionalidad, el bloque en América Latina incorpora normas de origen internacional, esencialmente los instrumentos de derechos humanos, dentro del parámetro de constitucionalidad. (Góngora, 2014, p. 308).

Entre los tribunales latinoamericanos se destaca la Corte Constitucional colombiana, quien tal como lo señala Góngora (2014), debido a "la visibilidad y reputación de [su] jurisprudencia (...) influenció significativamente los desarrollos constitucionales en los países de la Comunidad Andina", bien "como modelo durante procesos constituyentes (como ocurrió en Venezuela en 1999, Ecuador en 1998 y 2008, y Bolivia en 2009), o como referente con autoridad persuasiva en la jurisprudencia local, por ejemplo, en Bolivia y Perú” (p. 314).

En ese sentido, la Corte Constitucional colombiana, fundada en el corpus juris constitucional -especialmente en el artículo 93 de la Constitución Política (CP) - señaló que el bloque de constitucionalidad, en stricto sensu, está compuesto:

Por aquellas normas y principios que, sin aparecer formalmente en el articulado del texto constitucional, son utilizados como parámetro del control de constitucionalidad de las leyes, por cuanto han sido normativamente integrados a la Constitución, por diversas vías y por mandato de la propia Constitución". (CConst., C-225/95, A. Martínez, p. 94). 
De esta manera, se está frente a las normas previstas por el texto constitucional o que se integran a este directamente por uno de sus artículos, como el artículo 93 de la CP colombiana (CConst., C-358/97, pp. 80 y 81, fj. 6), que indica claramente: "los tratados y convenios internacionales ratificados por el Congreso que reconocen los derechos humanos y prohíben su limitación en los estados de excepción, prevalecen en el orden interno". Al igual las normas que pertenecen al jus cogens (CConst., C-027/93), como las reglas del derecho internacional humanitario (CConst., C-574/92).

Con lo anterior, se observa que de manera progresiva en el derecho constitucional las reglas y los principios provenientes del orden internacional -particularmente del derecho internacional de los derechos humanos- comienzan a integrarse al ordenamiento jurídico interno. Lo que ha cambiado la tarea del juez constitucional, quien ahora "no se limita a comparar solamente término a término dos textos, uno inferior, otro superior; sino a establecer inicialmente el término superior, luego a efectuar la comparación" (Favoreu, 1975, p. 41), antes de decidir sobre la compatibilidad normativa.

El contexto excepcional de "apertura al derecho internacional de los derechos humanos como al jus in bello" (Burgorgue-Larsen, 2009, p. 114) que vive en la actualidad el derecho constitucional, permite comprender que la "normatividad constitucional no es privilegio exclusivo de los artículos que formalmente integran el texto de la Carta Política" (CConst., C-067/03, p. 7). Ahora, la Grundnorm está compuesta "por un grupo más amplio de principios, reglas y normas de derecho positivo que conforman el denominado "bloque de constitucionalidad" y que comparten con los artículos del texto de la Carta la mayor jerarquía normativa en el orden interno" (CConst., C-067/03, p. 7).

Sin embargo, las nuevas realidades sociales han hecho que el bloque de constitucionalidad no se restrinja sino que sea concebido de manera mucho más amplia. Hay una transición conceptual de lo stricto a lo lato con el fin de dar respuesta a los actuales problemas jurídicos. Así, de manera paralela al bloque de constitucionalidad -compuesto por la Constitución, los principios y los tratados sobre derechos humanos-, la jurisprudencia de la Corte Constitucional colombiana ha elaborado una doctrina del bloque extendido, con el fin de encontrar en su contenido todos los elementos que le sirvan de parámetro para determinar la constitucionalidad de las normas internas (Estrada, 2006).

De acuerdo a la noción lato sensu, el bloque de constitucionalidad "estaría conformado no solo por el articulado de la Constitución sino, entre otros, por los tratados internacionales de que trata el artículo 93 de la Carta, por las leyes orgánicas y, en algunas ocasiones, por las leyes estatutarias" (CConst., C-191/98, p. 17, fj. 5).

Según la Corte Constitucional, las normas que hacen parte de esta noción extendida del bloque tienen características especiales que ayudan a su plena identificación. En primer lugar, 
ellas sirven de parámetro para realizar el control de constitucionalidad del derecho interno (CConst., C-225/95). De esta manera, en su labor de conformidad el juez constitucional debe confrontar la norma en cuestión a la luz de todos los elementos del bloque de constitucionalidad. Incluso, si se está frente a una reforma de la Constitución, pues en ese caso el juez debe tomar en cuenta los "límites intrínsecos al poder de reforma, ya que estos se encuentran reflejados en la Constitución misma o en los elementos del bloque de constitucionalidad" (CConst., C-574/11, p. 56, fj. 4.44). ${ }^{2}$ En otras palabras, del bloque en sentido lato.

En segundo lugar, ellas están investidas de rango normativo superior a las leyes ordinarias -ostentando en algunos casos la jerarquía intermedia entre la Constitución y la ley ordinaria-, y sirven como parámetro de control de constitucionalidad (CConst., C-191/98).

Finalmente, ellas hacen parte del bloque de constitucionalidad gracias a la remisión normativa expresa realizada por una disposición constitucional (CConst., C-191/98). Respecto a esta última característica, la Corte ha precisado que los tratados limítrofes del territorio, debido a la remisión expresa que de ellos efectúa el artículo 101 de la Constitución, forman "parte del bloque de constitucionalidad lato sensu". Por consiguiente, "las normas que ex- pidan las autoridades públicas no pueden contravenirlos a riesgo de ser declaradas inexequibles por violar el artículo 101 del Estatuto Superior" (CConst., C-191/98, p. 18, fj. 7).

Igualmente, la Corte a través de su desarroIlo jurisprudencial ha integrado al bloque de constitucionalidad los Convenios de la olT, los cuales, además de servir de parámetro de control, ayudan a interpretar mejor los derechos de las personas humanas. En la sentencia de constitucionalidad C-891 de 2002, la Corte estableció que el análisis de conformidad de las normas relativas a la "explotación de recursos naturales yacentes en territorios indígenas" debe tomar en cuenta todas "las disposiciones constitucionales -incluyendo los tratados internacionales que hacen parte del bloque de constitucionalidad, como es el caso del Convenio 169 de la olT-" (p. 46, fj. 6), en la medida en que "sirven como referente para interpretar los derechos de los trabajadores y para darle plena efectividad al principio de protección del trabajador y al derecho al trabajo" (CConst. C-617/08, p. 16, fj, 3.2.1).

En términos generales, "la doctrina del bloque de constitucionalidad [ha permitido] reconocer jerarquía constitucional a normas que no están incluidas en la Constitución nacional, usualmente con el fin de interpretarlas sistemáticamente con el texto de la Constitución" (Góngora, 2014, p. 301).

2. Ver también: Corte Constitucional de Colombia, Sentencia C-249/12, expedientes D-8673, D-8679 y D-8680, 22 de marzo de 2012, p. 35, fj 5.2.12. 
B. De lo nominado a lo innominado

Uno de los grandes avances del constitucionalismo ha sido la creación de catálogos de derechos definidos en las constituciones. Empero, como bien se sabe, la situación no siempre fue así, y el constitucionalismo de los Estados Unidos es prueba fehaciente de ello. La Constitución de Filadelfia de 1787 tenía una crucial característica: la falta de un catálogo explícito de derechos. Esta carencia se ha ido remediando progresivamente a través de los 27 "amendments" que dicho texto ha tenido a lo largo de su historia. Siendo el noveno el más importante al reconocer la existencia de derechos innominados o “unnamed-rights” (Black, 1991, p. 26).

Es preciso recordar que la novena enmienda de la Constitución de los Estados Unidos prescribe que "la enumeración de ciertos derechos en la Constitución no será interpretada como la negación o el menoscabo hacia otros retenidos por el pueblo". Además, es importante saber que esta enmienda ha sido la fuente de inspiración -a pesar de las ambigüedades históricas de su interpretación ${ }^{3}$ - de aquello que a futuro sería conocido en los textos constitucionales como "la cláusula de derechos implícitos" (Bidart, 2002, p. 108). Es decir, la cláusula constitucional que permitirá el reconocimiento de nuevos derechos en armonía con las nuevas realidades sociales.
Para Bidart (2002), el reconocimiento de derechos innominados dejó en evidencia "que hay derechos "con normas" y "sin normas" porque los derechos no se agotan en el catálogo escrito" (p. 104). Dicho reconocimiento también dejó la enseñanza de "no clausurar los derechos en casilleros rígidamente cerrados, porque el ritmo creciente de las necesidades y las valoraciones sociales demanda la movilidad de continuas añadiduras complementarias" (p. 104). Cuando la sociedad cambia el sistema jurídico debe seguirla y, por supuesto, reconocer otros derechos y adaptar los existentes a las nuevas realidades.

Las palabras de Bidart están en completa armonía con la teleología de la novena enmienda. En efecto, su análisis histórico demuestra que los fundadores estadounidenses además de ver en la enmienda la imposibilidad de reducir la protección de los derechos a la pobre, y en ocasiones, obsoleta literalidad de la Constitución, encuentran que crea límites precisos al ejercicio del poder federal. De hecho, puede decirse que los fundadores veían en la idea de derechos innominados la inclusión de derechos naturales (Lash, 2004). ${ }^{4}$ En otras palabras, los fundadores de los Estados Unidos enmarcaron la novena enmienda bajo dos connotaciones, una preventiva y otra constructiva. La primera hace referencia a la presunción que los derechos de las personas serían mejor protegidos por los Estados federados que por el Estado fe-

3. Por más de 150 años de jurisprudencia relativa a la novena enmienda, los derechos innominados fueron aplicados como límite al ejercicio del poder federal. Sin embargo, la Corte Suprema de Justicia progresivamente comenzó a utilizar la novena enmienda para extender el catálogo de derechos prescrito en la Constitución. Consultar al respecto: Lash (2005, 2008).

4. Ver también Williams (2011). 
deral, limitando así el poder de las autoridades de este último. La segunda sugiere la existencia de derechos más allá de los expresamente mencionados en el texto constitucional (Lash, 2004).

Por su parte, el constitucionalismo latinoamericano desarrolló la segunda connotación de la enmienda al establecer "cláusulas de apertura" (Fix-Zamudio citado por Bogdandy, 2014, p. 9), bien para la incorporación de nuevos derechos o para la complementación de derechos ya reconocidos en la mayoría de los textos constitucionales. Argentina fue uno de los primeros sistemas jurídicos en incorporar la cláusula de apertura de derechos innominados en su cuerpo normativo. El artículo 33 de la reforma constitucional de 1860 estableció que "las declaraciones, derechos y garantías que enumera la Constitución, no serán entendidas como negación de otros derechos y garantías no enumerados; pero que nacen del principio de soberanía del Pueblo y de la forma republicana de gobierno".

El desarrollo emprendido por Argentina se extendió hasta finales del siglo XX por toda Amé- rica, momento en el que la cláusula de derechos innominados ya había sido incorporada en la mayoría de los textos constitucionales del continente, con especiales refuerzos en lo atinente a los acuerdos y obligaciones internacionales de las entidades estatales. Uno de los primeros Estados en prever dicho refuerzo fue Colombia, con el artículo 94 de la Constitución de 1991. En este artículo, el constituyente precisó que "la enumeración de los derechos y garantías contenidos en la Constitución y en los convenios internacionales vigentes, no debe entenderse como negación de otros que, siendo inherentes a la persona humana, no figuren expresamente en ellos" (CP, 1991, art. 94). Enseguida, una norma similar fue incorporada por Ecuador, ${ }^{5}$ Venezuela ${ }^{6}$ y Bolivia, ${ }^{7}$ para consagrar en cada uno de esos órdenes jurídicos una cláusula de apertura de derechos innominados equivalente a la colombiana.

Gracias a la incorporación de cláusulas de derechos innominados en los sistemas jurídicos interamericanos se ha ampliado el catálogo de derechos por medio de la jurisprudencia nacional, llegando a reconocerse nuevos de-

5. Ecuador, siguiendo el ejemplo colombiano, incorporó en el artículo 19 de la Constitución de 1998 la cláusula de derechos innominados bajo este tenor: "Los derechos y garantías señalados en esta Constitución y en los instrumentos internacionales, no excluyen otros que se deriven de la naturaleza de la persona y que son necesarios para su pleno desenvolvimiento moral y material". En el artículo 11.7 de la Constitución de 2008, la cláusula se conservó así: "El reconocimiento de los derechos y garantías establecidos en la Constitución y en los instrumentos internacionales de derechos humanos, no excluirá los demás derechos derivados de la dignidad de las personas, comunidades, pueblos y nacionalidades, que sean necesarios para su pleno desenvolvimiento".

6. En el artículo 50 de la Constitución de Venezuela de 1961 ya existía la cláusula de derechos innominados sin hacer referencia a los acuerdos internacionales. Fue necesaria la llegada de la Constitución de 1999 -bastante influenciada por la Constitución colombiana de 1991- para ver en su artículo 22 una cláusula que incluyera dichos acuerdos.

7. El artículo 13.II de la Constitución boliviana de 2009 estableció: “Los derechos que proclama esta Constitución no serán entendidos como negación de otros derechos no enunciados". 
rechos (Williams, 2011). Por ejemplo, en los Estados Unidos se ha reconocido el derecho al aborto, ${ }^{8}$ fundado en "la noción de libertad individual existente en la decimocuarta enmienda" (Custos, 1995, p. 1122); y recientemente, el matrimonio a parejas del mismo sexo en el fallo Obergefell vs. Hodges. De acuerdo a este fallo, para la Corte Suprema el matrimonio es un derecho fundamental inherente a la libertad de la persona, de ahí que en virtud del due process y la equal protection de la decimocuarta enmienda, las parejas del mismo sexo no puedan ser privadas de este derecho y de esta libertad. ${ }^{9}$

Igualmente en Colombia se han reconocido nuevos derechos como el derecho al mínimo vital ${ }^{10}$ y el derecho a la estabilidad laboral reforzada, ${ }^{11}$ provenientes de la dignidad humana, la solidaridad y la igualdad (CConst., T-427/92, p. 5, fj. 7). Al respecto, la Corte Constitucional colombiana ha dicho:

La Constitución otorga protección jurídica a diversos sectores, grupos o personas en situación de desventaja, marginamiento o de- bilidad manifiesta (CP. art. 13). Sectores de la población como los niños (CP. art. 44), los ancianos (CP. art. 46), los minusválidos (CP. art. 47), las minorías étnicas (CP. art. 7) etc., deben recibir una especial protección del Estado por voluntad del constituyente. De esta forma se busca promover las condiciones para que la igualdad sea real y efectiva y no simplemente un parámetro formal que deje intocadas las desigualdades sustanciales que se presentan en la sociedad. (Sentencia T-427/92, p. 5, fj. 7).

Así y en definitiva, en el continente americano la incorporación de la cláusula de apertura en los textos constitucionales se entendió desde la connotación constructiva dada por los fundadores estadounidenses en la novena enmienda. Esto es, aquella que ve en los derechos innominados la existencia de un número superior de derechos que no se encuentran en el contenido de la Constitución escrita (Williams, 2011, p. 568). Además, dicha cláusula fue recepcionada como mecanismo para separar el derecho constitucional de lo que podría denominarse el "positivismo de la normativi-

8. En 1973, el fallo Roe vs. Wade de la Corte Suprema de Justicia de los Estados Unidos autorizó por primera vez la interrupción voluntaria del embarazo. A partir de ese momento, dicho fallo se convirtió en la piedra angular del derecho a la libertad individual de las mujeres en los Estados Unidos, ya que dispuso la modificación de las leyes federales y estatales que sancionaban el aborto (Supreme Court of the United States, 1973).

9. Ver al respecto: Supreme Court of the United States (2015).

10. El derecho al mínimo vital "es consecuencia directa de los principios de dignidad humana y de Estado Social de Derecho que definen la organización política, social y económica justa acogida como meta por el pueblo de Colombia en su Constitución” (CConst., T-426/92, p. 7, fj. 5).

11. De acuerdo a la jurisprudencia de la Corte Constitucional, se trata de la estabilidad reforzada del trabajo para sujetos de especial protección constitucional. En 1996, esta protección fue creada para proteger a las trabajadoras en estado de embarazo a través del fuero de maternidad. Justo un año después, la protección fue ampliada para proteger otros sujetos, como los trabajadores investidos de fuero sindical, al igual que las personas con discapacidad (CConst., T-568-96, p. 6, fj. 5; C-470-97, p. 13, fj. 8). 
dad escrita" (Bidart, 2002, 110), con el fin de crear ordenamientos jurídicos más dinámicos con las realidades y más congruentes con las necesidades de los seres humanos.

Por otra parte, la congruencia buscada en los ordenamientos jurídicos con la cláusula de derechos innominados fue tan bien recibida por los jueces nacionales, que estos se comprometieron con ella, inspirándose en los principios y en los derechos ya existentes, para realizar su trabajo de identificación de nuevos derechos (Bidart, 2002), confirmando con esto "el aumento de la autoridad de los jueces" (DelmasMarty, 2007, p. 95) -en tanto promotores de la dignidad humana como del orden justo-, y probando que el poder de estos es "el más universalizable, así como también el más universalizante, de los tres poderes descritos por Montesquieu" (Allard y Garapon, 2005, p. 84).

No obstante, la facultad de los jueces de descubrir en su actividad interpretativa nuevos derechos trasciende las fronteras nacionales para volverse una práctica constante en el seno de los tribunales internacionales. Mediante esta práctica se concreta un diálogo entrelazado no solamente entre las jurisdicciones nacionales e internacionales, sino una integración al derecho interno de las reglas y principios de los derechos humanos a través de la creación de un "foro mundial de jueces" (Allard y Garapon, 2005, p. 84).

Un repaso de los principales instrumentos internacionales sobre derechos humanos confirmará esta apreciación. En el orden universal, por ejemplo, el Pacto Internacional de Derechos Civiles y Políticos (PIDCP), al igual que el Pacto Internacional de Derechos Sociales, Económicos y Culturales (PIDESC), establecen la "saving clause" (Sepúlveda, 2003, p. 303) en sus artículos 5.2:

No podrá admitirse restricción o menoscabo de ninguno de los derechos humanos fundamentales reconocidos o vigentes en un Estado Parte en virtud de leyes, convenciones, reglamentos o costumbres, so pretexto de que el presente Pacto no los reconoce o los reconoce en menor grado.

Esta cláusula de protección, si bien no tiene la misma fraseología de las cláusulas de los derechos innominados ya vistos, sí conserva en su contenido la teleología de la novena enmienda de la Constitución de Filadelfia. Es decir, la apertura del catálogo de protección a otros derechos, por ser inherentes a la persona y estar en relación con la dignidad humana. EI artículo 5.2 común pone en juego también la aplicación del principio pro homine en la medida en que prescribe "que en caso de definiciones concurrentes de un mismo derecho, el nivel de protección ofertado por [los Pactos] no representa sino un estándar mínimo que deberá borrarse frente a un nivel de garantía más elevada" (Mazeron, 2011, p. 171).

De manera similar la Convención Europea de Derechos Humanos (CEDH) en su artículo 60 -artículo 53 a partir del Protocolo No. 11- estableció una cláusula de apertura de derechos humanos, del siguiente tenor: 
Ninguna de las disposiciones del presente Convenio se interpretará en el sentido de limitar o perjudicar aquellos derechos humanos y libertades fundamentales que podrían ser reconocidos conforme a las leyes de cualquier Alta Parte Contratante o en cualquier otro Convenio en el que ésta sea parte.

Con el mismo propósito, pero de una manera mucho más elaborada que la CEDH (Chirdaris, 2011, p. 81), la Convención Americana sobre Derechos Humanos (CADH) estableció en su artículo 29 una cláusula de apertura para la protección de los derechos humanos en tres partes (Bidart, 2002). La primera, formada por el literal b), enuncia que ninguna disposición de la CADH puede ser interpretada de manera que limite "el goce y ejercicio de cualquier derecho o libertad que pueda estar reconocido de acuerdo con las leyes de cualquiera de los Estados Partes o de acuerdo con otra convención en que sea parte uno de dichos Estados".

La segunda, integrada por el literal c) e inspirada fuertemente por la reforma constitucional argentina de 1860, agrega que las disposiciones de la $\mathrm{CADH}$ no pueden ser interpretadas de manera que sean "[excluidos] otros derechos y garantías inherentes al ser humano o que se derivan de la forma democrática representativa de gobierno".

La tercera, compuesta por el literal d), culmina el contenido del artículo 29, estableciendo que ninguna interpretación de la CADH puede hacerse en el sentido de "excluir o limitar el efecto que puedan producir la Declaración Americana de Derechos y Deberes del Hombre y otros actos internacionales de la misma naturaleza".

Por su parte, la Carta Africana de Derechos Humanos y de los Pueblos (CADHP) si bien no reconoce de manera literal la cláusula de apertura a nuevos derechos, una interpretación de su artículo 60 da luces al respecto. En primer lugar, el artículo 60 establece que la Comisión al igual que la Corte Africana, ${ }^{12}$ se inspiran en el ejercicio de sus funciones en "la legislación internacional sobre derechos humanos y de los pueblos".

En segundo lugar, el artículo complementa el reenvío y la apertura normativa de la Carta, inicialmente hacia las "disposiciones de los diversos instrumentos africanos referentes a los derechos humanos y de los pueblos, la Carta de las Naciones Unidas, la Carta de la Organización de la Unidad Africana [y] la Declaración Universal de los Derechos Humanos". Para enseguida afirmar que la Carta también se inspira en "otros instrumentos adoptados por las Naciones Unidas y por los países africanos en materia de derechos humanos y de los pueblos" como en "las disposiciones de los diversos instrumentos adoptados por departamentos especializados de las Naciones Unidas de los cuales los firmantes de la presente Carta sean miembros". Entre ellas, es necesario

12. Esto en virtud del artículo 2 del Protocolo adicional a la CADHP de 1998 que dio nacimiento a la Corte Africana de Derechos Humanos y de los Pueblos. 
precisar, se encuentran aquellas del PIDCP y del PIDESC que fueron ratificadas por la mayoría de Ios Estados africanos, ${ }^{13}$ lo que los compromete con la cláusula de protección prescrita en el artículo 5.2 de estos instrumentos.

Sea cual sea la manera por la que esos instrumentos internacionales se han abierto a otras normas jurídicas, englobando el conjunto de fuentes del derecho interno y del derecho internacional -como lo han hecho los dos Pactos de Naciones Unidas (PIDCP y PIDESC), la CEDH y la $\mathrm{CADH}-$, los jueces internacionales de derechos humanos han aprovechado el reenvío normativo para aplicarlos en su labor judicial.

En el ejercicio de esta empresa, los jueces han demostrado que el sujeto jurídico directamente protegido es el ser humano, aplicando los instrumentos internacionales de la manera que mejor garantice la protección integral de las eventuales víctimas de las violaciones de derechos humanos. Además, ellos han tomado en cuenta que la interpretación de dichos instrumentos debe ser "evolutiva" y "progresiva" (Rodríguez, 2014, p. 710).

Así lo han hecho saber, por ejemplo, los jueces de la Corte Europea de Derechos Humanos (European Court of Human Rights -ECHR) en la interpretación de la CEDH a la luz de la evolución del derecho internacional. En el caso Varnava and others, que trata sobre la desaparición forzada de nueve personas que se sos- pecha haber "desaparecido después de ser aprehendidas por las fuerzas militares turcas en 1974" sin que "las autoridades turcas hayan dado alguna indicación de lo que les había ocurrido desde ese momento" (ECHR, 2009, § 3), la ECHR (2009) precisó dos cosas. Inicialmente, que "la Convención es un mecanismo de protección de derechos humanos y que es de crucial importancia que sea interpretada y aplicada de manera que garantice derechos concretos y específicos, y no teóricos e ilusorios" (§ 160). Luego, en relación con el derecho a la vida, concretó:

El artículo 2 debe ser interpretado en la medida de lo posible a la luz de los principios del derecho internacional, sobre todo de las reglas del derecho internacional humanitario, que juegan un rol indispensable y universalmente reconocido en la salvaguarda y en la inhumanidad de los conflictos armados. (ECHR, 2009, § 185).

Respecto a esto, recientemente en una opinión disidente, el juez Pinto de Albuquerque (2015) recordó que "en virtud del artículo 53 de la Convención, si el derecho internacional humanitario prevé un grado de protección más elevado que la Convención, los Estados partes no pueden invocar la Convención para sustraerse del respeto del derecho internacional humanitario" ( $\$ 20$, nota a pie de página 23). Esto, porque la cláusula de apertura del artículo 53, “que va en el sentido del artículo 31 § 3 c) de

13. Consultar el estado de ratificaciones del PIDCP y del PIDESC en United Nations (2015a, 2015b). 
la Convención de Viena sobre el derecho de los tratados, ofrece a la Corte un gran potencial de aplicación del derecho internacional humanitario" (§ 20).

Por otro lado, los jueces de la Corte IDH, aplicando la cláusula de apertura prevista en el artículo 29 de la CADH, dieron nacimiento a uno de los derechos humanos contemporáneos que más aceptación ha tenido en los organismos $^{14} \mathrm{e}$ instrumentos internacionales, ${ }^{15}$ a pesar de las discusiones que su reconocimiento suscitó en algunos tribunales, como aquel del sistema europeo de protección. ${ }^{16}$

Se trata del derecho a la verdad cuyo reconocimiento por la Corte IDH inició en 1988 en el caso Velásquez Rodríguez vs. Honduras (González-Salzeberg, 2008). Vale la pena recordar que en este caso, en el que se determinó la responsabilidad internacional estatal por la desaparición forzada de un estudiante por miembros de las fuerzas armadas hondureñas, la Corte precisó que "el Estado está (...) obligado a investigar toda situación en la que se hayan violado los derechos humanos protegidos por la Convención" (1988, § 176). Con el fin de garantizar "el derecho de los familiares de la víctima de conocer cuál fue el destino de ésta" y de poder determinar "dónde se encuentran sus restos" (§ 181).

Vía jurisprudencial, la Corte IDH continuó desarrollando el derecho a la verdad tanto en su ámbito individual como en su ámbito colectivo (Groome, 2011). En el individual, a partir de la relación de la verdad con las garantías judiciales (art. 8 CADH) (1998, Caso Blake vs. Guatemala, § 102) y la protección judicial (art. 25 CADH) (2000, Caso Durand y Ugarte vs. Perú, $\S 130)$. Así fue fijado en la sentencia de fondo del caso Bámaca Vélasquez vs. Guatemala, donde la Corte determinó:

El derecho a la verdad se encuentra subsumido en el derecho de la víctima o sus familiares a obtener de los órganos competentes del Estado el esclarecimiento de los hechos violatorios y las responsabilidades correspondientes, a través de la investigación y el

14. Human Rights Committee (2003, § 10.2; 2006, § 12.2). Human Rights, Chamber for Bosnia and Herzegovina (2003, § 191). International Criminal Court (2008, § 32).

15. Convención Internacional para la protección de todas las personas contra las desapariciones forzadas de 2006 (artículo 24 $\S 2$ ); Human Rights Council, Resolution 9/11 (2008), A/HCR/RES/9/11, 18 September 2008 y Resolution 12/12 (2009), A/ HCR/RES/12/12, 1 October 2009. Consultar igualmente: Naqvi (2006) y Naftali (2013).

16. El reconocimiento del derecho a la verdad en el seno de la ECHR ha sido controversial. En el 2011, a pesar de que la Corte resaltó, por primera vez, en el caso Association "21 December 1989" and others v. Romania, la importancia del derecho de las víctimas y de sus familiares a "conocer la verdad sobre las circunstancias de los acontecimientos que implican la violación masiva de derechos tan fundamentales como la vida". Los votos razonados de los jueces de dicho organismo en el caso ElMasri v. Macedonia, comprueban que en Europa dicho derecho es aún el centro de fuertes discusiones. Ver: ECHR. Case of Association "21 December 1989" and others v. Romania, 2011, § 144; Tulkens, Spielmann, Sicilianos y Keller (2012). Ver también: Casadevall y López Guerra (2012). Sin embargo, es claro que en estos últimos años la ECHR y sus jueces han comenzado a integrar a su jurisprudencia el derecho a la verdad. ECHR, Case Margus v. Croatia (2014, § 199). Consultar también: Ziemele, De Gaetano, Laffranque y Keller (2013, § 9). Igualmente: Pinto de Albuquerque (2014, § 7, nota a pie de página 24). 
juzgamiento que previenen los artículos 8 y 25 de la Convención. (2000, § 201).

En cambio, el ámbito colectivo se ha construido con base en el derecho a la información (art. 13 CADH) al igual que sobre el derecho que tiene la sociedad de conocer la verdad. Para la Corte IDH está claro que la interpretación conjunta de los artículos 8, 25 y 13 de la $\mathrm{CADH}$, le reconoce a toda persona el derecho a conocer la verdad (2010, caso Gomes Lund y otros vs. Brasil). ${ }^{17} \mathrm{Sin}$ embargo, para la Corte la obligación que debe cumplir el Estado de dar a conocer la verdad de los hechos es una modalidad de reparación para los familiares de las víctimas, así como para la sociedad en su conjunto (Corte IDH, 2002, caso Bámaca Vélasquez vs. Guatemala). Algunos ejemplos muy precisos sobre el tema ayudarán a comprender mejor este ámbito.

En el caso Niños de la calle vs. Guatemala, la Corte IDH condenó al Estado a denominar un centro educativo con un nombre alusivo a los niños víctimas de secuestro, tortura y asesinato causados por la omisión de las autoridades estatales (2001, § 103 y punto resolutivo n. ${ }^{\circ}$ 7). En la reparación del caso Barrios Altos, la Corte estableció que debido a la violación del derecho a la vida de quince personas y del derecho a la integridad de otras cuatro, Perú tenía la obligación de "publicar la sentencia de la Corte en el Diario Oficial El Peruano, y difundir su contenido en otros medios de co- municación" (2001, punto resolutivo n. ${ }^{\circ}$ 5. d.), presentar perdón público a las víctimas por los graves daños infligidos, al igual que construir un monumento en su homenaje (Corte IDH, 2001). Un poco más reciente, en el caso Contreras y otros vs. Salvador la Corte ordenó al Estado "realizar un audiovisual documental sobre la desaparición forzada de niños y niñas durante el conflicto armado en El Salvador, con mención específica del presente caso, en el que se incluya la labor realizada por la Asociación Pro-Búsqueda de Niños y Niñas Desaparecidos" (2011, punto resolutivo n. ${ }^{\circ}$ 9). Con el fin de "ser transmitido mensualmente, por tres ocasiones, en el canal y el horario de mayor audiencia televisiva y [de] ser colocado en la página web de búsqueda de niños y niñas desaparecidos" (§ 209).

De acuerdo a la Corte IDH (2002), las medidas preventivas y de no repetición que conforman el derecho a la verdad comienzan con la revelación y reconocimiento de las atrocidades del pasado, ya que la sociedad tiene el derecho de conocer la verdad sobre tales crímenes con el propósito de tener la capacidad de prevenirlos en el futuro. El fiel respeto del derecho a la verdad garantiza que en el mañana las graves violaciones de derechos humanos no se repitan (Caso Bámaca Vélasquez vs. Guatemala).

Por otro lado, en África la Comisión Africana de Derechos Humanos y de los Pueblos (African

17. Ver también: Corte IDH, caso Gelman vs. Uruguay, Sentencia de fondo y reparaciones, Serie $C n^{\circ} 221,24$ de febrero de 2011 , $\S$ 243; y caso Contreras y otros vs. Salvador, Sentencia de fondo, reparaciones y costas, Serie $\mathrm{C} \mathrm{n}^{\circ} 232,31$ de agosto de 2011, § 173. 
Commission on Human and Peoples' Rights -ACHPR), a través del artículo 60 de la CADHP ha integrado nuevos derechos humanos en el sistema de protección africano. En esta labor, la ACHPR recuerda con frecuencia en sus decisiones el fundamento textual de su actuar utilizando la misma fórmula (IIla, 2013):

Conforme a los artículos 60 y 61 de la Carta africana, la Comisión ha examinado la presente comunicación a la luz de las disposiciones de la Carta africana y de los instrumentos y principios regionales e internacionales pertinentes de derechos humanos. (ACHPR, 2001, § 49). ${ }^{18}$

Así la ACHPR, inspirándose en la jurisprudencia interamericana, reconoció la existencia en África del derecho a la "propiedad comunitaria". ${ }^{19}$

El caso Endorois Welfare Council vs. Kenya, que trata sobre el desplazamiento de sus tierras de miembros de la comunidad indígena Endorois, con la clasificación hecha por el gobierno keniano de dichos territorios como zona protegida, afectando su manera ancestral de vivir, así como todo su proceso de desarrollo, fue la oportunidad adecuada para que la ACHPR reconociera el derecho a la propiedad en su perspectiva colectiva y precisara si este fue desconocido por el Estado de Kenia (ACHPR, 2009, § 144).

La primera actuación adelantada por la ACHPR, fundada en los casos Moiwana ${ }^{20}$ y Saramaka ${ }^{21}$ de la Corte IDH, fue el reconocimiento de los Endorois como un pueblo indígena susceptible de ser protegido por la Carta africana (ACHPR, 2009). La segunda actuación, dirigida en esta oportunidad a resolver el nudo gordiano del asunto, fue la interpretación del artículo 14 de la CADHP. ${ }^{22}$ A este respecto, la ACHPR concluyó, por un lado, que "Ios Endorois tienen derecho a la propiedad de sus territorios ancestrales, las posesiones y los animales que hacen parte

18. Ver también: ACHPR (2003, § 47).

19. Cuatro años antes al reconocimiento del derecho a la propiedad colectiva por parte de la ACHPR, el informe del grupo de trabajo de expertos sobre las poblaciones/comunidades indígenas llamó la atención sobre la pérdida de tierras por parte de las "comunidades pastoriles y de cazadores-recolectores indígenas de África". Según el informe, este fenómeno de despojo ha sido facilitado, de una parte "por las ideas según las cuales las tierras ocupadas por los pastores y los cazadores-recolectores eran terra nullius"; y por otra, debido a que "la legislación nacional no prevé la adquisición de tierras de propiedad colectiva". En el mismo informe se precisó también que la "posesión colectiva es fundamental para la mayoría de los indígenas" y por esta razón, "una de las principales solicitudes hechas por las comunidades indígenas es (...) el reconocimiento y la protección de estas formas de posesión colectiva de tierras” (ACHPR, 2015, p. 12).

20. Se trata de un caso sobre la pretendida denegación al acceso a la justicia y del desplazamiento de la comunidad Moiwana, que tuvo lugar después de que las fuerzas armadas de Surinam atacaron la población Moiwana el 29 de noviembre de 1986 (Corte IDH, 2006).

21. Los hechos de este caso versan sobre la alegada omisión del Estado de Surinam de no tomar las medidas eficaces para reconocer a los miembros de la Comunidad Saramaka el derecho de propiedad sobre los territorios que tradicionalmente han ocupado y utilizado. De no permitirle a los miembros del pueblo Saramaka el acceso efectivo a la justicia, en tanto comunidad, para la protección de sus derechos fundamentales. Igualmente, de no haber cumplido con la obligación de adoptar disposiciones de derecho interno y respetar los derechos enunciados en la Convención (Corte IDH, 2007, caso Saramaka).

22. Artículo 14. Estará garantizado el derecho a la propiedad. Este solamente podrá ser usurpado en el interés público o general de la comunidad y de conformidad con las disposiciones de las leyes adecuadas. 
de ellos"; por el otro, que "el derecho de los Endorois a la propiedad fue violado, sobre todo por la expropiación, y la negación efectiva de la propiedad de sus tierras" (ACHPR, 2009, § 184). Para llegar a esta conclusión, la ACHPR retomó los argumentos dados por la Corte IDH en el caso Mayagna (Sumo) Awas Tingn vs. Nicaragua (2001, §§ 140. b) y 151), afirmando:

La Convención Interamericana protege los derechos de propiedad en un sentido que involucra, entre otros, los derechos de los miembros de las comunidades indígenas en el marco de la propiedad comunitaria y sostiene que la posesión de la tierra debería ser suficiente para las comunidades indígenas carentes de títulos reales para la obtención y el reconocimiento oficial de dicha propiedad. (ACHPR, 2009, § 190).

Enseguida la ACHPR, inspirándose en el caso Saramaka vs. Suriname (Corte IDH, 2007, §§ 87-96), consideró que así como "la expulsión de la población de sus hogares era una violación del artículo 14 de la Carta africana (...) el no reconocimiento de un grupo indígena o tribal se convierte en una violación del derecho a la propiedad" (ACHPR, 2009, §§ 191 y 192), en la medida en que:

El Estado tiene siempre el deber de reconocer el derecho a la propiedad de los miembros de la comunidad Endoroise, en el marco de un sistema de propiedad comunitaria, y de fijar los mecanismos necesarios para brindarle un efecto jurídico nacional a un derecho reconocido por la Carta y el derecho internacional. (ACHPR, 2009, § 196).
Como se puede ver, la ACHPR, gracias a la cláusula de apertura del artículo 60 de la CADHP, decidió integrar al derecho africano de los derechos humanos y de los pueblos la evolución del derecho internacional en relación con el derecho a la propiedad, al reconocer la existencia del derecho a la propiedad colectiva, tal como ya lo había hecho años antes la Corte IDH en su jurisprudencia. La existencia de este nuevo derecho será confirmada y reforzada por el precedente jurisprudencial de la ACHPR en el 2013, en un caso iniciado por el Frente de Liberación del Estado de Cabinda contra Angola, en el que se buscó la "reivindicación de la autodeterminación económica del pueblo de Cabinda y, en particular, sobre la disposición y explotación de los recursos petroleros, minerales y naturales on shore" (ACHPR, 2013, § 54). En esa oportunidad, la ACHPR reafirmó:

Existe el derecho de propiedad colectiva o comunitaria, el cual es un elemento del derecho a la propiedad estipulado en el artículo 14 de la Carta. Tal como sucede con el derecho a la propiedad individual, el derecho a la propiedad comunitaria involucra el deber para un Estado de reconocer y proteger el disfrute pacífico de la propiedad por un grupo o pueblo, con las solas restricciones del Estado basadas en la necesidad pública o en el interés general y conforme a las disposiciones de las leyes apropiadas. (2013, § 104).

Ahora bien, con los ejemplos dados se puede constatar que el descubrimiento de derechos innominados, vía cláusulas de apertura, es lógico y va conforme al objeto y fin de los instru- 
mentos de derechos humanos analizados. En especial, si se toma en cuenta que es imposible que a través de ellos se logre garantizar todos los derechos humanos y libertades fundamentales reconocidos en el derecho internacional. Sin duda, es factible que los administrados de los Estados partes de dichos instrumentos encuentren una protección más amplia en el derecho interno o en acuerdos internacionales. Por ello, sería contrario a la ratio legis de los instrumentos sobre derechos humanos que las disposiciones más protectoras del individuo se encuentren limitadas por una interpretación cerrada y restringida (Velu y Ergec, 2014).

Finalmente, el uso de las cláusulas de apertura y el descubrimiento de derechos innominados dinamizaron la construcción jurisprudencial, la determinación del derecho aplicable -llenando las lagunas dejadas por las normas o las nociones indeterminadas-y el desarrollo notorio del derecho interno mediante la integración de reglas y principios del derecho internacional de los derechos humanos. Sin embargo, es preciso aclarar que la integración de normas internacionales al derecho nacional es reforzada a través del fenómeno de la convencionalización del derecho interno.

\section{EL BLOQUE DE CONVENCIONALIDAD ¿LA ANTÍTESIS?}

La relación semántica entre convencionalidad y constitucionalidad trae consigo una consecuencia: cada vez que se hace referencia al bloque de convencionalidad viene a la imaginación del lector la expresión bloque de constitucionalidad. A decir verdad esta relación conceptual no es insignificante ni caprichosa. El bloque de convencionalidad en sí se construyó a semejanza del bloque de constitucionalidad, sobre la idea misma de una pirámide normativa al estilo kelseniano, constituida por normas superiores que validan normas inferiores (Alberton, 2005). En otras palabras, el bloque de convencionalidad se construyó "por aproximación al [bloque de constitucionalidad] para designar un conjunto de normas que se sitúan fuera de la esfera normativa interna" (Alberton, 2005, p. 252). No obstante, la idea de un bloque de convencionalidad conformado por un conjunto de normas homogéneas se ha consolidado por medio del diálogo armónico entre jueces internos e internacionales de derechos humanos.

Antes de continuar con esta noción es preciso indicar que si el término convencionalidad parece a simple vista hacer alusión exclusiva a las convenciones internacionales, así como constitucionalidad pareciera hacer referencia solo a la Constitución, dicho término se concibió - por la vía interpretativa de los juecescon el objetivo de reagrupar bajo una misma idea el conjunto de normas internacionales provistas de autoridad supraconstitucional. Así, "si toda convención internacional hace parte de un tal bloque, este integra igualmente y paradoxalmente los actos no calificables como convenciones e incluso las normas no escritas" (Alberton, 2005, p. 255).

Una perfecta ilustración de este fenómeno es el sistema interamericano de protección, en 
donde bien es sabido que sus jueces, basados en el artículo 2 de la $\mathrm{CADH}^{23}$-artículo que valga decirlo no tiene equivalente en la CEDH (Ferrer, $2013)^{24}$ y tan solo una pequeña aproximación en la CADHP ${ }^{25}$ - dotaron de superioridad las normas interamericanas, al precisar que los Estados tienen la obligación de adoptar las medidas de derecho interno necesarias para aplicarlas y hacerlas efectivas. ${ }^{26}$ Es decir, para Ios jueces interamericanos la CADH -superando la estéril discusión del rango normativo que le haya atribuido el derecho estatal a las normas internacionales- obliga a los Estados a "adoptar, con arreglo a sus procedimientos constitucionales y a las disposiciones de esta Convención, las medidas legislativas o de otro carácter que fueren necesarias para hacer efectivos tales derechos y libertades". ${ }^{27}$

Con esto han logrado los jueces de la Corte IDH que su jurisprudencia "busque privilegiar una aproximación en ruptura con el "positivismo jurídico" poniendo en tela de juicio el fundamento voluntarista del derecho internacional en beneficio de un derecho "verdaderamente universal" aplicable tanto a los Estados como a los seres humanos" (Hennebel, 2007, p. 65). [Comillas y cursivas en el original].

Véase cómo a imagen y semejanza del bloque de constitucionalidad, que en el derecho interno sirve de parámetro de control de constitucionalidad, en el derecho interamericano se construyó la noción de bloque de convencionalidad, también para servir de parámetro del control de convencionalidad de las normas internas (MuriIlo, 2013), al igual que para garantizar la obtención de una aplicación armoniosa de estas (García, 2015, pp. 137 y 137). Así fue precisado por el expresidente de la Corte IDH, Eduardo Ferrer Mac-Gregor, en uno de sus votos razonados:

En principio, el parámetro del "control difuso de convencionalidad" por parte de los jueces nacionales (con independencia de si ejercen o no control de constitucionalidad), es el Pacto de San José y la jurisprudencia de la Corte IDH que la interpreta. $(2010, \S 44) .{ }^{28}$

23. "Artículo 2. Deber de adoptar disposiciones de derecho interno. Si el ejercicio de los derechos y libertades mencionados en el artículo 1 no estuviere ya garantizado por disposiciones legislativas o de otro carácter, los Estados Partes se comprometen a adoptar, con arreglo a sus procedimientos constitucionales y a las disposiciones de esta Convención, las medidas legislativas o de otro carácter que fueren necesarias para hacer efectivos tales derechos y libertades."

24. Ver también: Burgorgue-Larsen (2014).

25. “Artículo 1. Obligaciones de los Estados Parte: Los Estados miembros de la Organización para la Unidad Africana firmantes de la presente Carta reconocerán los derechos, deberes y libertades contemplados en esta Carta y se comprometerán a adoptar medidas legislativas o de otra índole con el fin de llevarlos a efecto."

26. Ver en otras: Corte IDH, Caso Suárez Rosero vs. Ecuador, 1997, §§ 98 y 99; Caso Garrido y Baigorria vs. Argentina, 1998, §§ 67 y 71; Caso Castillo Páez vs. Perú, 1998, §§ 105 y punto resolutivo n. ${ }^{\circ} 2$; Caso Castillo Petruzzi y otros vs. Perú, $1999, \S$ 207 y punto resolutivo n. ${ }^{\circ}$ 14; Caso Almonacid Arrellano vs. Chile, 2006, § 121 y puntos resolutivos n.os 2-6.

27. Consultar al respecto: Ministerio Público Fiscal de la Ciudad Autónoma de Buenas Aires (2013).

28. Según el propio expresidente de la Corte IDH, el "control difuso de convencionalidad" nació el año 2006 paralelamente al "control de convencionalidad" ejercido por la Corte IDH a partir del caso Almonacid Arellano vs. Chile. Se trata en concreto 
En efecto, la Corte IDH (2006) en su jurisprudencia constante ha afirmado que en el ejercicio del control de convencionalidad debe tomarse en cuenta no solamente la $\mathrm{CADH}$, sino también la interpretación que de ella realiza la Corte, intérprete última de la Convención Americana (Caso Almonacid Arrellano vs. Chile). ${ }^{29}$

Sin embargo, el bloque de convencionalidad concebido por los jueces interamericanos es más amplio (Dulitzky, 2015). En el caso Trabajadores Cesados del Congreso vs. Perú, es el ex juez interamericano Sergio García Ramírez quien en su voto razonado aclara qué elementos hacen parte de este bloque. En dicho voto se confirma, en primera medida, que respecto al control de convencionalidad la Corte IDH ha tenido en cuenta "la aplicabilidad y aplicación de la Convención Americana sobre Derechos Humanos" (García, 2006, § 2). Luego, establece que en el análisis de compatibilidad normativa, es necesario tener en cuenta también

otros instrumentos de igual naturaleza [que la $\mathrm{CADH}$ ], integrantes del corpus juris convencional de los derechos humanos de los que es parte el Estado: Protocolo de San Salvador, Protocolo relativo a la Abolición de la
Pena de Muerte, Convención para Prevenir y Sancionar la Tortura, Convención de Belém do Pará para la Erradicación de la Violencia contra la Mujer, Convención sobre Desaparición Forzada, etcétera. (García, 2006, § 2).

Lo anterior muestra que el bloque de convencionalidad "no solo comprende la Convención Americana, sino también los otros "Protocolos" adicionales a la misma así como otros instrumentos internacionales que han sido motivo de integración al corpus juris interamericano por parte de la jurisprudencia de la Corte IDH" (Ferrer, 2010, § 47).

Por otro lado, y gracias al diálogo jurisdiccional entrelazado que han sostenido los jueces interamericanos por medio del artículo 29 de la CADH (Fretes, 2014), ${ }^{30}$ el contenido del bloque de convencionalidad se ha concebido de manera amplia, evolutiva y progresiva (Rodríguez, 2014, p. 710). En la opinión consultiva sobre el derecho a la información en la asistencia consular, la Corte IDH resaltó:

El corpus juris del Derecho Internacional de los Derechos Humanos está formado por un conjunto de instrumentos internacionales de

de un control que debe inicialmente ser realizado por todos los jueces nacionales de los Estados que pertenecen al sistema interamericano, pero también por las otras autoridades que cumplan funciones públicas. Este control, como instrumento procesal para la garantía de los derechos humanos, y debido a la "internacionalización del derecho constitucional", tiene el objetivo de proteger los derechos humanos previstos en los pactos internacionales luego que los mecanismos constitucionales no son suficientes. Es por esto que con el bloque de convencionalidad se configura en cierta medida una "supremacía convencional" (§ 21).

29. Ver también Corte IDH: Caso Boyce y otros vs. Barbados, 2007, § 78; Caso Radilla Pacheco vs. México, 2009, § 339; Caso Rosendo Cantú vs. México, 2010, § 219; Caso Ibsen Cárdenas e Ibsen Peña vs. Bolivia, 2010, § 202; Caso Cabrera García y Montiel Flores vs. México, 2010, § 225. Consultar igualmente: Caso Liakat Ali Alibux vs. Surinam, 2014, § 87.

30. Consultar también: Torres Kirmser (2014, pp. 65-74). 
contenido y efectos jurídicos variados (tratados, convenios, resoluciones y declaraciones). Su evolución dinámica ha ejercido un impacto positivo en el Derecho Internacional, en el sentido de afirmar y desarrollar la aptitud de este último para regular las relaciones entre los Estados y los seres humanos bajo sus respectivas jurisdicciones. Por lo tanto, esta Corte debe adoptar un criterio adecuado para considerar la cuestión sujeta a examen en el marco de la evolución de los derechos fundamentales de la persona humana en el derecho internacional contemporáneo. (1999, Opinión Consultiva OC-16/99, § 115).

Así, se tiene un bloque de convencionalidad amplio que debe en todo momento ser tomado en cuenta por el juez internacional de los derechos humanos, pero sobre todo, por el juez nacional, toda vez que como lo afirma el juez interamericano Diego García-Sayán se está frente a un proceso vivo en el que se están produciendo importantes interacciones entre el derecho internacional y el derecho interno (2005, p. 326). Respecto a esto, Ferrer MacGregor (2010), sostiene:

Los jueces nacionales deben atender a este "bloque", lo que implica, por parte de ellos, una permanente actualización de la jurisprudencia de la Corte IDH y propicia una "viva interacción" entre las jurisdicciones nacionales y la interamericana, con la finalidad última de establecer estándares en nuestra región para la protección efectiva de los derechos humanos. ( $\$ 50)$. [Comillas en el original].
Entonces, la interacción jurisdiccional nacional e internacional alrededor del bloque de convencionalidad, obliga al juez interno a:

Aplicar la jurisprudencia convencional incluso la que se crea en aquellos asuntos donde no sea parte el Estado nacional al que pertenece, ya que lo que define la integración de la jurisprudencia de la Corte IDH es la interpretación que ese Tribunal Interamericano realiza del corpus juris interamericano con la finalidad de crear un estándar en la región sobre su aplicabilidad y efectividad. (Ferrer, 2010, § 51). [Cursivas en el original].

Además, el bloque de convencionalidad "puede ser válidamente ampliado en sede nacional cuando se otorgue mayor efectividad a [los] derecho[s] humano[s]" (Ferrer, 2011, p. 532). Con esto, el dinamismo del bloque de convencionalidad se asegura en la medida que la Corte IDH puede inspirarse e integrar a su jurisprudencia, a partir de la technique des références croisées (Hennebel, 2007, p. 31), los criterios establecidos por las jurisdicciones nacionales, las decisiones de los organismos de otros sistemas regionales, las resoluciones de los Comités de Naciones Unidas o del Consejo de Derechos Humanos. Incluso, las recomendaciones de la Comisión IDH, y los informes de órganos de la OEA o de Naciones Unidas.

A título ejemplificativo, del derecho nacional la Corte IDH integró a su jurisprudencia el criterio establecido por la Corte Constitucional colombiana en relación con el estatuto de los desplazados. Desde ese momento, la Corte IDH sos- 
tiene que no es en esencia el registro formal frente a los agentes del gobierno lo que le da el carácter de desplazado a un individuo, sino el simple hecho de haberse visto obligado a dejar su lugar de residencia habitual (2006, caso Masacre de Ituango vs. Colombia). ${ }^{31}$

Respecto de las decisiones de otros sistemas regionales de protección, en tratándose del tema de si el embrión puede considerarse persona y esta consideración puede llegar a impedir la práctica de la fecundación in vitro por la violación del derecho a la vida -debido a la pérdida embrionaria que esta técnica involucra-, el tribunal interamericano utilizó los criterios decantados por la jurisprudencia de la ECHR sobre el asunto, para concluir “que el embrión no puede ser entendido como persona para efectos del artículo 4.1 de la Convención Americana". Lo anterior, en la medida que el embrión solo, sin ser implantado en el útero, no da lugar a la "concepción" en el sentido del artículo 4.1 citado (caso Artavia Murillo y otros ("fecundación in vito") vs. Costa Rica, 2012, $\S \S 76,234$ - 242 et 264).

Asimismo, las resoluciones de los Comités de Naciones Unidas han tenido gran aplicación. En la solución del caso Atala Riffo vs. Chile, que versa sobre la discriminación de una mujer homosexual respecto a la custodia de sus hijas, la Corte IDH (2012) se apoyó en observaciones dadas sobre la familia por el Comité para la Eliminación de todas las Formas de
Discriminación contra la Mujer, el Comité de Derechos del Niño y el Comité de Derechos Humanos, para ultimar, respecto al concepto de familia, que no existe un modelo único y que esta puede perfectamente estar conformada por una pareja homosexual y sus hijos.

Por otro lado, desde inicios del siglo XXI, la Corte IDH se ha inspirado en las recomendaciones de la Comisión IDH en varios temas. Entre ellos, el derecho de propiedad de las poblaciones indígenas. En el caso Comunidad Mayagna (Sumo) Awas Tingni vs. Nicaragua, fue la Comisión quien solicitó el reconocimiento del derecho a la propiedad colectiva de las comunidades indígenas. Esto, debido a que para sus miembros "el territorio global de la comunidad es poseído colectivamente y los individuos y familias gozan de derechos subsidiarios de uso y ocupación". A partir de esta reflexión, y por medio de la aplicación del artículo 29 de la $\mathrm{CADH}$, la Corte IDH (2001) fue el primer tribunal internacional del mundo en reconocer como nuevo derecho la propiedad colectiva o comunitaria (§§ 140, 142, 148 y 149).

Sobre los informes de los órganos de Naciones Unidas, recientemente, en el caso de Personas dominicanas y haitianas expulsadas vs. República Dominicana, la Corte IDH (2014) tomó en cuenta el informe sobre los derechos de los No-Ciudadanos del Alto Comisionado de las Naciones Unidas para los Derechos Humanos, para estatuir sobre la prohibición de expulsio-

31. Ver en otras: Corte IDH. Caso de las Comunidades Afrodescendientes desplazadas de la Cuenca del Río Cacarica (Operación Génesis) vs. Colombia, 2013, § 428. 
nes colectivas. Así como para sancionar al Estado dominicano por la violación del derecho a la libertad personal de quienes fueron expulsados colectivamente, sin garantizarles, de manera adecuada, el análisis y estudio de sus circunstancias personales.

Con estos ejemplos, se deja en evidencia la amplitud que en el sistema interamericano ha adquirido el bloque de convencionalidad y el enriquecimiento permanente que de él realiza la Corte IDH. Además, se prueba la versatilidad y dinamicidad que tiene dicha institución para solucionar los problemas jurídicos más disímiles y exigentes del continente.

\section{LA SÍNTESIS DEL CORPUS JURIS COMÚN INTERAMERICANO}

El corpus juris común interamericano en la actualidad es un concepto de gran relevancia en el sistema regional de derechos humanos creado para América. Como lo afirma Rodolfo Arango (2014), parafraseando al filósofo John Searle,

para que algo o alguien cumpla una función que en sí no tiene se requiere, por sobre todo, una intencionalidad colectiva, esto es, el reconocimiento y la aceptación de que el objeto o la persona tienen una función de estatus. (P. 25).

Es esto lo que precisamente está ocurriendo con las normas del bloque de convencionalidad y del bloque de constitucionalidad, que al ser aplicadas armónicamente por los jueces y las demás autoridades públicas, le dan al corpus juris interamericano el estatus de función de regulación universal.

Dicha fuerza universal de regulación legitima el actuar de los jueces internacionales de derechos humanos y, por corolario, de todas las autoridades públicas nacionales, que en diálogo permanente con estos van progresivamente aceptando y adoptando las soluciones planteadas por ellos para resolver problemas jurídicos. Lo que en definitiva ha hecho evolucionar el derecho americano, pudiéndose decir que al interior del continente se "vive una primavera democrática basada en el aumento del uso de los derechos individuales y colectivos como mecanismo de reconocimiento social y cultural" (Arango, 2014, p. 26). Incluso, se afirma por algunos que ese esfuerzo de articulación le dio forma al "ius constitutionale commune latinoamericano", con el único fin de fortalecer el Estado de derecho, la democracia y los derechos humanos en la región (Piovesan, 2014, p. 61). [Comillas y cursivas en el original].

Lo cierto es que la realidad internacional evidencia que los jueces son los constructores actuales del nuevo orden jurídico global (Slaughter, 2005). Ejemplo de ello son los jueces interamericanos, quienes basados en normas de carácter general, enajenadas de la insipiente discusión monista y dualista, e inspiradas en el discurso del pluralismo jurídico, prefieren las soluciones pro homine sobre las soluciones radicales fundadas en egos nacionalistas o internacionalistas (Bogdandy, 
2014). Construyendo, en definitiva, un international law for humankind (Cançado, 2013, pp. 635-644) y un common law of human rights (McCrudden, 2000, pp. 499-532), por medio del diálogo normativo pluralista en el que se rechaza la idea de jerarquía y se prefiere la construcción colectiva entre los distintos niveles normativos (estatal, supranacional e internacional) (Bogdandy, 2014).

Así lo han hecho saber los jueces de la Corte IDH (1982), quienes desde su primera Opinión Consultiva (OC-1/82), y en aras de lograr la materialización de la justicia, hicieron énfasis en que "la unidad de naturaleza del ser humano y el carácter universal de los derechos y libertades que merecen garantía, están en la base de todo régimen de protección internacional" (§ 40). Unidad y universalidad reconocidas en el artículo 29 de la CADH en cuanto "se opone, en términos bastantes claros, a restringir el régimen de protección de los derechos humanos atendiendo a la fuente de las obligaciones que el Estado haya asumido en esa materia" (§ 41). En consecuencia, si a una misma situación son aplicables la Convención Americana, otro tratado internacional, inclusive una norma interna, debe prevalecer la norma más favorable a la persona humana (Corte IDH, 1985, OC-5/85).

Lo anterior porque "los tratados modernos sobre derechos humanos, en general, y, en particular, la Convención Americana, no son tratados multilaterales de tipo tradicional, concluidos de un intercambio recíproco de derechos, para el beneficio mutuo de los Estados contratantes" (Corte IDH, 1982, OC-2/82, §
29). En ese orden de ideas, las normas internas e internacionales tendientes a proteger los derechos humanos, como complementarias que son, forman el corpus juris común interamericano, debiéndose por los jueces, en cada caso concreto, "preferir, privilegiar o favorecer la aplicación de aquella norma que otorgue una mayor protección a los derechos de la persona, independientemente si dicha norma se encuentra en un tratado internacional o en una disposición de derecho interno" (Rodríguez, 2014, p. 711).

Así, bajo el marco del corpus juris interamericano, los conceptos bloque de constitucionalidad y bloque de convencionalidad lejos de ser opuestos, son complementarios, actúan en común y en beneficio del ser humano. Podría decirse incluso que los dos, al tener la misma función -servir de parámetro de control- (Ferrer, 2011), ayudan en general a todas las autoridades públicas en su quehacer funcional, y en particular a los jueces en su labor de humanización del derecho internacional de los derechos humanos (Cançado, 2013).

De esta manera, las autoridades públicas y los jueces de derechos humanos entienden que existe un marco jurídico común interamericano, que debe ser interpretado y aplicado de la manera más favorable al ser humano, en el cual existe un bloque normativo convencional y un bloque normativo constitucional, que deben ser minuciosamente estudiados al momento de resolver problemas jurídicos. En la realización de esta empresa deben los jueces, inicialmente, estudiar el bloque convencional 
para evitar incompatibilidades entre la norma interna y la internacional; luego, el bloque constitucional para identificar si en él existen normas o interpretaciones normativas mucho más protectoras, con el fin de hacerlas primar sobre la norma o interpretación internacional.

Finalmente, la composición heterogénea del corpus juris común interamericano clausura el debate entre constitucionalistas e internacionalistas sobre la integración de normas internacionales al orden interno y sobre el valor de estas, asociando a los unos con los otros en un objetivo común: la protección máxima de los derechos del ser humano y de la humanidad.

\section{CONCLUSIONES}

En su trasegar histórico el bloque de constitucionalidad logró el reconocimiento y la integración de normas que literalmente no componen el texto de la Constitución, ampliando su espectro de protección y trayendo consigo dos resultados. Primero, la integración al orden interno de todos los desarrollos del derecho internacional de los derechos humanos. Segundo, la creación de una unidad normativa tendiente a extender la protección del ser humano así como a materializar y preservar su dignidad.

Sumado a lo anterior, la evolución del derecho internacional de los derechos humanos y la interpretación que de él realizan los jueces han dado lugar a un bloque de convencionalidad que hoy es referente obligado para todas las autoridades nacionales, y por medio del cual se integra a la reflexión jurídica el principio pro homine. Demostrándose así, cómo en aras de lograr la protección efectiva de los derechos de las personas no debe ni puede existir contraposición entre los bloques normativos. Requiriéndose, por el contrario, una articulación entre ellos, un corpus juris común, que desde el pluralismo jurídico favorezca la norma que en mejor y mayor medida proteja al ser humano, sea esta del orden interno o del orden internacional (Bogdandy, 2014). Pues nuevamente el derecho, tal como lo pensaron los padres del derecho internacional, visualiza con agudeza al ser humano como su razón de ser, su fin primordial, su sujeto máximo de protección.

\section{Referencias}

1. African Commission on Human and Peoples' Rights. (27 October 2001). Communication 155/96. Social and Economic Rights Action Center, Center for the Economic and Social Rights (SERAC) vs. Nigeria.

2. African Commission on Human and Peoples' Rights. (29 May 2003). Communication 228/99. Law offices of Ghazi Suleiman vs. Soudan.

3. African Commission on Human and Peoples' Rights. (25 November 2009). Communication 276/03. Centre for Minority Rights development (Kenya) and Minority Rights Group (on behalf of Endorois Welfare Council) vs. Kenya. 
4. African Commission on Human and Peoples' Rights. (5 November 2013). Communication 328/06. Front for the Liberation of the State of Cabinda vs. Republic of Angola.

5. African Commission on Human and Peoples' Rights. (25 June 2015). Report of the African Commission's working group on indigenous populations/communities. Adopted by the African Commission on human and people's rights at its 28th ordinary session, Benin, 2000. Obtenido de achpr: http://www.achpr.org/files/special-mechanisms/indigenous-populations/expert_report_on_indigenous_communities.pdf

6. Alberton, G. (2005). De l'indispensable intégration du bloc de conventionnalité au bloc de constitutionnalité? Revue française de droit administratif, (2), 249-268.

7. Allard, J. y Garapon, A. (2005). Les juges dans la mondialisation: la nouvelle révolution du droit. Paris: Seuil.

8. Arango Rivadeneira, R. (2014). Fundamentos del ius constitutionale commune en América Latina: derechos fundamentales, democracia y justicia constitucional. En A. V. Bogdandy, H. Fix-Fierro y M. Morales Antoniazzi (Coords.), lus constitutionale commune en América Latina: rasgos, potencialidades y desafíos (págs. 25-36). México: Universidad Nacional Autónoma de México.

9. Argentina. (1860). Reforma constitucional.
10. Bidart Campos, G. J. (2002). Los derechos "no enumerados" en su relación con el derecho constitucional y el derecho internacional. En R. Méndez Silva (Coord.), Derecho internacional de los derechos humanos. Memoria del VII Congreso Iberoamericano de Derecho Constitucional. México: Universidad Nacional Autónoma de México.

11. Black Jr, C. L. (1991). "One nation indivisible": Unnamed Human Rights in the States. St. John's Law Review, 65(1), 17-57.

12. Bogdandy, A. V. (2014). Ius constitutionale commune latinoamericanum: una aclaración conceptual. En A. V. Bogdandy, H. FixFierro y M. Morales Antoniazzi (Coords.). lus constitutionale commune en América Latina: rasgos, potencialidades y desafíos (págs. 3-23), México: Universidad Nacional Autónoma de México.

13. Burgorgue-Larsen, L. (2009). De l'internationalisation du dialogue des juges. Missive doctrinale à l'attention de Bruno Genevois. En B. Genevois (Ed.), Le dialogue des juges: mélanges en l'honneur du président Bruno Genevois. Paris: Dalloz.

14. Burgorgue-Larsen, L. (2014). Chronique d'une théorie en vogue en Amérique latine Décryptage du discours doctrinal sur le contrôle de conventionalité. Revue française de droit constitutionnel, (100), 831-863.

15. Cançado Trindade, A. A. (2013). International law for humankind: towards a new jus 
gentium. Leiden: Martinus Nijhoff Publishers.

16. Casadevall, J. y López Guerra, L. (13 December 2012). Concurring Opinions. En European Court of Human Rights. Case ElMasri vs. Macedonia.

17. Casadevall, J. y López Guerra, L. (13 December 2012). Concurring Opinions, Case El-Masri v. Macedonia. Application No. 39630/09.

18. Constituyente. (1991). Constitución Política de Colombia.

19. Corte Constitucional de Colombia. Sentencia T-426/92 (M. P.: Eduardo Cifuentes Muñoz; junio 24 de 1992).

20. Corte Constitucional de Colombia. Sentencia T-427/92. (M. P.: Eduardo Cifuentes Muñoz; junio 24 de 1992). Expediente T-824.

21. Corte Constitucional de Colombia. Sentencia C-574/92 (M. P.: Ciro Angarita Barón; octubre 28 de 1992).

22. Corte Constitucional de Colombia. Sentencia C-027/93 (M. P.: Simón Rodríguez Rodríguez; febrero 5 de 1993).

23. Corte Constitucional de Colombia. Sentencia C-225/95 (M. P.: Alejandro Martínez Caballero; mayo 18 de 1995).

24. Corte Constitucional de Colombia. Sentencia T-568/96 (M. P.: Eduardo Cifuentes Muñoz; octubre 28 de 1996). Expediente T-100861.
25. Corte Constitucional de Colombia. Sentencia C-358/97 (M. P.: Eduardo Cifuentes Muñoz; agosto 5 de 1997). Expediente T-100861.

26. Corte Constitucional de Colombia. Sentencia C-470/97 (M. P.: Alejandro Martínez Caballero; septiembre 25 de 1997). Expediente D-1606.

27. Corte Constitucional de Colombia. Sentencia C-191/98 (M. P.: Eduardo Cifuentes Muñoz; mayo 6 de 1998).

28. Corte Constitucional de Colombia. Sentencia C-891/02 (M. P.: Jaime Araujo Rentería; octubre 22 de 2002).

29. Corte Constitucional de Colombia. Sentencia C-067/03 (M. P.: Marco Gerardo Monroy Cabra; febrero 4 de 2003).

30. Corte Constitucional de Colombia. Sentencia C-617/08 (M. P.: Rodrigo Escobar Gil; junio 25 de 2008).

31. Corte Constitucional de Colombia. Sentencia C-574/11 (M. P.: Juan Carlos Henao Pérez; julio 22 de 2011).

32. Corte Constitucional de Colombia. Sentencia C-249/12 (M. P.: Juan Carlos Henao Pérez; marzo 29 de 2012).

33. Corte Interamericana de Derechos Humanos. (24 de septiembre de 1982). El efecto de las reservas sobre la entrada en vigen- 
cia de la Convención Americana sobre Derechos Humanos (Arts. 74 y 75). Opinión Consultiva OC-2/82.

34. Corte Interamericana de Derechos Humanos. (24 de septiembre de 1982). "Otros tratados" objeto de la función consultiva de la Corte (art. 64 Convención Americana sobre Derechos Humanos). Opinión Consultiva OC-1/82.

35. Corte Interamericana de Derechos Humanos. (13 de noviembre de 1985). La colegiación obligatoria de periodistas (arts. 13 y 29 Convención Americana sobre Derechos Humanos). Opinión Consultiva OC$5 / 85$.

36. Corte Interamericana de Derechos Humanos. (20 de julio de 1988). Caso Velásquez Rodríguez vs. Honduras. Sentencia de fondo, Serie C n. ${ }^{\circ} 4$.

37. Corte Interamericana de Derechos Humanos. (12 de noviembre 1997). Caso Suárez Rosero vs. Ecuador. Sentencia de fondo, Serie $\mathrm{C}$. ${ }^{\circ} 35$.

38. Corte Interamericana de Derechos Humanos. (24 de enero de 1998). Caso Blake vs. Guatemala. Sentencia de fondo, Serie C n. ${ }^{\circ} 36$.

39. Corte Interamericana de Derechos Humanos. (27 de noviembre de 1998). Caso Castillo Páez vs. Perú. Sentencia de reparaciones y costas, Serie $C n .{ }^{\circ} 43$.
40. Corte Interamericana de Derechos Humanos. (27 de agosto de 1998). Caso Garrido y Baigorria vs. Argentina. Sentencia de reparaciones y costas, Serie $\mathrm{C} n{ }^{\circ} 39$.

41. Corte Interamericana de Derechos Humanos. (30 de mayo de 1999). Caso Castillo Petruzzi y otros vs. Perú. Sentencia de fondo, reparaciones y costas, Serie $\mathrm{C} n{ }^{\circ} 52$.

42. Corte Interamericana de Derechos Humanos. (1 de octubre de 1999). El derecho a la información sobre la asistencia consular en el marco de las garantías del debido proceso legal. Opinión Consultiva OC-16/99.

43. Corte Interamericana de Derechos Humanos. (25 de noviembre de 2000). Caso Bámaca Vélasquez vs. Guatemala. Sentencia de fondo, Serie $\mathrm{C}$. ${ }^{\circ} 70$.

44. Corte Interamericana de Derechos Humanos. (16 de agosto de 2000). Caso Durand y Ugarte vs. Perú. Sentencia de fondo, Serie C n. ${ }^{\circ} 68$.

45. Corte Interamericana de Derechos Humanos. (30 de noviembre de 2001). Caso Barrios Altos vs. Perú. Sentencia de reparaciones y costas, Serie $C$ n. ${ }^{\circ} 87$.

46. Corte Interamericana de Derechos Humanos. (31 de agosto de 2001). Caso Comunidad Mayagna (Sumo) Awas Tingni vs. Nicaragua. Sentencia de fondo, reparaciones y costas, Serie $\mathrm{C} n{ }^{\circ} 79$. 
47. Corte Interamericana de Derechos Humanos. (26 de mayo de 2001). Caso "Niños de la calle" (Villagrán Morales y otros) vs. Guatemala. Sentencia de reparaciones y costas, Serie C n. ${ }^{\circ} 77$.

48. Corte Interamericana de Derechos Humanos. (22 de febrero de 2002). Caso Bámaca Velásquez vs. Guatemala. Sentencia de reparaciones y costas, Serie $\mathrm{C} n .^{\circ} 91$.

49. Corte Interamericana de Derechos Humanos. (26 de septiembre de 2006). Caso Almonacid Arrellano vs. Chile. Sentencia de excepciones preliminares, fondo, reparaciones y costas, Serie C n. 154.

50. Corte Interamericana de Derechos Humanos. (14 de julio de 2006). Caso de la Comunidad Moiwana vs. Surinam. Sentencia de excepciones preliminares, fondo reparaciones y costas, Serie C n. 124.

51. Corte Interamericana de Derechos Humanos. (1 de julio de 2006). Caso Masacre de Ituango vs. Colombia. Sentencia de excepciones preliminares, fondo, reparaciones y costas, Serie C n. ${ }^{\circ} 148$

52. Corte Interamericana de Derechos Humanos. (20 de noviembre de 2007). Caso Boyce y otros vs. Barbados. Sentencia de excepciones preliminares, fondo, reparaciones y costas, Serie C n. 169.

53. Corte Interamericana de Derechos Humanos. (20 de noviembre de 2007). Caso del
Pueblo Saramaka vs. Surinam, Sentencia de excepciones preliminares, fondo, reparaciones y costas, Serie $C n^{\circ} 172$.

54. Corte Interamericana de Derechos Humanos. (23 de noviembre de 2009). Caso Radilla Pachecho vs. México, Sentencia de excepciones preliminares, fondo, reparaciones y costas, Serie C n. 209.

55. Corte Interamericana de Derechos Humanos. (24 de noviembre de 2010). Caso Gomes Lund y otros (Guerrilha do Araguaia) vs. Brasil. Sentencia de excepciones preliminares, fondo, reparaciones y costas, Serie $\mathrm{C}$ n. ${ }^{\circ} 219$.

56. Corte Interamericana de Derechos Humanos. (1 de septiembre de 2010). Caso Ibsen Cárdenas e Ibsen Peña vs. Bolivia. Sentencia de excepciones preliminares, fondo, reparaciones y costas, Serie C n. 217.

57. Corte Interamericana de Derechos Humanos. (31 de agosto de 2010). Caso Rosendo Cantú vs. México. Sentencia de excepciones preliminares, fondo, reparaciones y costas, Serie C n. ${ }^{\circ} 216$.

58. Corte Interamericana de Derechos Humanos. (31 de agosto de 2011). Caso Contreras y otros vs. Salvador. Sentencia fondo, reparaciones y costas, Serie C n. ${ }^{\circ} 232$.

59. Corte Interamericana de Derechos Humanos. (24 de febrero de 2011). Caso Gelman 
vs. Uruguay. Sentencia de fondo y reparaciones, Serie $\mathrm{C} n .^{\circ} 221$.

60. Corte Interamericana de Derechos Humanos. (28 de noviembre de 2012). Caso Artavia Murillo y otros ("fecundación in vito") vs. Costa Rica. Sentencia de excepciones preliminares, fondo, reparaciones y costas, Serie C n. 257.

61. Corte Interamericana de Derechos Humanos. (24 de febrero de 2012). Caso Atala Riffo vs. Chile. Sentencia de fondo, reparaciones y costas, Serie C n. 239.

62. Corte Interamericana de Derechos Humanos. (20 de noviembre de 2013). Caso de las Comunidades Afrodescendientes desplazadas de la Cuenca del Río Cacarica (Operación Génesis) vs. Colombia. Sentencia de excepciones preliminares, fondo, reparaciones y costas, Serie C n. 270.

63. Corte Interamericana de Derechos Humanos. (30 de enero de 2014). Caso Liakat Ali Alibux vs. Surinam. Sentencia de excepciones preliminares, fondo, reparaciones y costas, Serie C n. 276.

64. Corte Interamericana de Derechos Humanos. (28 de agosto de 2014). Caso de Personas dominicanas y haitianas expulsadas vs. República Dominicana. Sentencia de excepciones preliminares, fondo, reparaciones y costas, Serie C n. 282.

65. Cottier, T. y Hertig, M. (2003). The prospects of 21st century constitutionalism.
Max Planck Yearbook of United Nations Law, 7(1), 261-322.

66. Custos, D. (1995). La Cour suprême américaine et la liberté d'avortement. Revue du droit public et de la science politique en France et à l'étranger, (5), 1119-1155.

67. Chirdaris, V. (2011). The limits of interpretation of the Strasbourg Court and the principle of non-regression. En D. Spielmann, M. Tsirli, \& P. Voyatzis (Edits.), The European Convention on human rights, a living instrument: Essays in honour of Christos L. Rozakis, (págs. 81-106). Bruxelles: Bruylant.

68. Delmas-Marty, M. (2007). Mondialisation et montée en puissance des juges. En Université Libre de Bruxelles, Le dialogue des juges (Actes du colloque organisé le 28 avril 2006 à l'Université libre de Bruxelles) (págs. 95-114), Bruxelles: Bruylant.

69. Denizeau, C. (1997). Existe-t-il un bloc de constitutionnalité; meìmoire pour le diplome d'eitudes approfondies de droit public interne. Paris: Librairie Générale de Droit \& de Jurisprudence.

70. Dulitzky, A. E. (2015). An Inter-American Constitutional Court? The Invention of the Conventionaly Control by the Inter-American Court of Human Rights. Texas International Law Journal, 50(1), 45-93.

71. Dworkin, R. (2012). Los derechos en serio. Barcelona: Ariel. 
72. Eisenmann, C. (1928). La justice constitutionnelle et la Haute cour constitutionneIle d'Autriche. Paris: Librairie Générale de Droit \& de Jurisprudence.

73. Émeri, C. y Serin, J. L. (1970). Les suites du référendum et l'élection présidentielle de 1969: les modifications apportées au règlement de l'Assemblée nationale. Revue du droit public, (3), 637-759.

74. Estrada Vélez, S. I. (2006). Los principios jurídicos y el bloque de constitucionalidad. Medellín: Universidad de Medellín.

75. European Court of Human Rights [ECHR]. (18 September 2009). Case Varnava and others vs. Turkey. Application $n^{\circ} 16064 / 90,16065 / 90,16066 / 90$, 16068/90, 16069/90, 16070/90, $16071 / 90,16072 / 90$ and 16073/90.

76. European Court of Human Rights [ECHR]. (28 November 2011). Case of Association "21 December 1989" and others vs. Romania. Applications n. ${ }^{\circ} 33810 / 07$ and $18817 / 08$.

77. European Court of Human Rights [ECHR]. (27 May 2014). Case Margus vs. Croatia. Application no. 4455/10.

78. Favoreu, L. (1975). Le principe de constitutionnalité. Essaie de définition d'après la jurisprudence du Conseil constitutionnel. En M. Waline (Ed.), Recueil d'études en hommage à Charles Eisenmann (págs. 3348). Paris: Cujas.
79. Ferrer Mac-Gregor, E. (26 de noviembre de 2010). Voto razonado de la sentencia de fondo, reparaciones y costas. En Corte Interamericana de Derechos Humanos. Caso Cabrera García y Montiel Flores vs. México. Sentencia de fondo, reparaciones y costas, Serie $\mathrm{C} n .^{\circ} 220$.

80. Ferrer Mac-Gregor, E. (2011). Interpretación conforme y control difuso de convencionalidad. El nuevo paradigma para el juez mexicano. Estudios Constitucionales, 9(2), 531-622.

81. Ferrer Mac-Gregor, E. (2013). Eficacia de la sentencia interamericana y la cosa juzgada internacional: vinculación directa hacia las partes (res judicata) e indirecta hacia los Estados parte de la Convención Americana (res interpretata) (Sobre el cumplimiento del caso Gelman vs. Uruguay). Estudios Constitucionales, 11(2), 641-694.

82. Fretes, A. (2014). El diálogo jurisprudencial sobre los derechos humanos, aporte eficaz para nuestras democracias latinoamericanas. Revista Jurídica de la Facultad de Derecho y Ciencias Sociales. Universidad Nacional de Asunción, 57-64.

83. García Ramírez, S. (24 de noviembre de 2006). Voto razonado de la sentencia de excepciones preliminares, fondo, reparaciones y costas. En Corte Interamericana de Derechos Humanos. Caso Trabajadores Cesados del Congreso (Aguado Alfaro y otros) vs. Perú. Sentencia de excepciones 
preliminares, fondo, reparaciones y costas, Serie C n. ${ }^{\circ} 158$.

84. García Ramírez, S. (2015). The Relationship between Inter-American Jurisdiction and States (National Systems): Some Pertinent Questions. Notre Dame Journal of International \& Comparative Law, 5(1), 115-152.

85. García-Sayán, D. (2005). Una viva interacción: Corte Interamericana y Tribunales Internos. En Corte Interamericana de Derechos Humanos, La Corte Interamericana de Derechos Humanos: un cuarto de siglo: 1979-2004 (págs. 325-384) San José: Corte Interamericana de Derechos Humanos.

86. Góngora Mera, M. E. (2011). Inter-American judicial constitutionalism: on the constitutional rank of human rights treaties in Latin America through national and interAmerican adjudication. San José: InterAmerican Institute on Human Rights.

87. Góngora Mera, M. E. (2014). La difusión del bloque de constitucionalidad en la jurisprudencia latinoamericana y su potencial en la construcción del ius constitutionale commune latinoamericano. En A. V. Bogdandy, H. Fix-Fierro, y M. Morales Antoniazzi (Coords.), lus constitutionale commune en América Latina: rasgos, potencialidades y desafíos (págs. 301-327). México: Universidad Nacional Autónoma de México.

88. González-Salzeberg, D. (2008). El derecho a la verdad en situaciones de post-conflicto bélico de carácter no-internacional. International Law: Revista Colombiana de Derecho Internacional, (12), 435-467.

89. Groome, D. (2011). The Right to Truth in the Fight against Impunity. Berkeley Journal of International Law, 29(1), 175-199.

90. Hennebel, L. (2007). Les références croisées entre les juridictions internationales des droits de l'homme. En Université Libre de Bruxelles, Le dialogue des juges. Actes du colloque organisé le 28 avril 2006 à l'Université libre de Bruxelles (págs. 3176). Bruxelles: Bruylant.

91. Human Rights Chamber for Bosnia and Herzegovina. (3 March 2003). The "Srebrenica Cases" Decision on admissibility and merits. Cases n.os $\mathrm{CH} / 01 / 8365$ and others.

92. Human Rights Committee. (3 April 2003). Case Schedko et Bondarenko vs. Belarus. Communication n. ${ }^{\circ}$ 886/1999, U.N. Doc. CCPR/C/77/D/886/1999.

93. Human Rights Committee. (11 April 2006). Case Mariam, Philippe, Auguste and Thomas vs. Burkina Faso. Communication n. ${ }^{\circ} 1159 / 2003$, U.N. Doc. CCPR/ C/86/D/1159/2003.

94. Illa Maikassoua, R. (2013). La Commission africaine des droits de l'homme et des peuples. Paris: Karthala. 
95. International Criminal Court. (13 May 2008). Case Prosecutor vs. Germain Katanga and Mathieu Ngudjolo Chui. Decision on the Set of Procedural Rights Attached to Procedural Status of Victims at the Pre-Trial Stage of the Case, ICC01/04-01/07-474.

96. Lash, K. T. (2004). The Lost Original Meaning of the Ninth Amendment. Texas Law Review, 83(2), 331-429.

97. Lash, K. T. (2005). The Lost Jurisprudence of the Ninth Amendment. Texas Law Review, 83(3), 708-716.

98. Lash, K. T. (2008). Of Inkblots and Originalism: Historical Ambiguity and the Case of the Ninth Amendment. Harvard Journal of Law \& Public Policy, 31(2), 467-472.

99. Mazeron, F. (2011). Article 5. En E. Decaux y F. Martin (Dirs.), Le pacte international relatif aux droits civils et politiques. Commentaire article par article (págs. 165-175), Paris: Economica.

100. McCrudden, C. (2000). A Common Law of Human Rights? Transnational Judicial Conversations on Constitutional Rights. Oxford Journal Legal Studies, 20(4), 499-532

101. Ministerio Público Fiscal de la Ciudad Autónoma de Buenas Aires. (2013). Diálogos: el impacto del sistema interamericano en el ordenamiento interno de los Estados. Buenos Aires: Eudeba.
102. Murillo Cruz, D. A. (2013). El control de convencionalidad y su consolidación en América. Revista Nueva Época, XIX(41), 69-86.

103. Naftali, P. (2013). La construction du droit à la vérité en droit international: une ressource ambivalente à la croisée de plusieurs mobilisations. Thèse de Doctorat: Sciences Juridiques. Université Libre de Bruxelles. Bruxelles.

104. Naqvi, Y. (2006). The right to the truth in international law: fact or fiction? International Review of the Red Cross, 88(862), 245-273.

105. Pinto de Albuquerque, P. (17 September 2014). Dissenting Opinion. En European Court of Human Rights. Case Mocanu and others vs. Romania. Applications n.os 10865/09, 45886/07 and 32431/08.

106. Pinto de Albuquerque, P. (16 July 2015). Dissenting Opinion. En European Court of Human Rights. Case Sargsyan vs. Azerbaïdjan.

107. Piovesan, F. (2014). Ius constitutionale commune latinoamericano en derechos humanos e impacto del sistema interamericano: rasgos, potencialidades y desafíos. En A. V. Bogdandy, H. Fix-Fierro y M. Morales Antoniazzi (Coords.), Ius constitutionale commune en América Latina: rasgos, potencialidades y desafíos (págs. 61-81). México: Universidad Nacional Autónoma de México. 
108. Rodríguez, G. (2014). Artículo 29. Normas de Interpretación. En C. Steiner y P. Uribe (Edits.), Convención Americana sobre Derechos Humanos. Comentario (págs. 706712). Bogotá: Konrad Adenauer Stiftung.

109. Sepúlveda, M. (2003). The Nature of the Obligation under the International Covenant on Economic, Social and Cultural Rights. New York: Intersentia.

110. Slaughter, A. M. (2005). A new world order. Princeton: Princeton University Press.

111. Supreme Court of the United States. (22 January 1973). Case Roe vs. Wade. 410 U.S. 113, 93 S. Ct. 705, 35 L. Ed. 2d 147.

112. Supreme Court of the United States. (27 June 2015). Case Obergefell vs. Hodges.

113. Torres Kirmser, J. R. (2014). Diálogo jurisprudencial entre la justicia nacional y las cortes internacionales. Revista Jurídica de la Facultad de Derecho y Ciencias Sociales. Universidad Nacional de Asunción, 65-74.

114. Tulkens, F., Spielmann, D., Sicilianos, L. A. y Keller, H. (13 December 2012). Concurring Opinions. En European Court of Human Rights. Case El-Masri vs. Macedonia. Application n³9630/09.

115. United Nations. (10 de junio de 2015a). International Covenant on Civil and Political Rights: Status of ratification, re- servation and declarations. Recuperado de United Nations Treaty Collection: https://treaties.un.org/Pages/ViewDetails.aspx?src=TREATY\&mtdsg_no $=$ IV$4 \&$ chapter $=4 \&$ lang $=$ en\&clang $=\_$en

116. United Nations. (10 de junio de 2015b). International Covenant on Economic, Social and Cultural Rights: Status of ratification, reservation and declarations. Recuperado de United Nations Treaty Collection: https://treaties.un.org/Pages/ViewDetails.aspx?src=TREATY\&mtdsg_no $=$ IV$3 \&$ chapter $=4 \&$ lang $=$ en \&clang $=\_$en

117. Velu, J. y Ergec, R. (2014). Convention européenne des droits de l'homme. BruxeIles: Bruylant.

118. Walter, C. (2007). International law in a process of constitutionalization. En J. Nijman y A. Nollkaemper (Edits.), New Perspectives on the Divide between National \& International Law (págs. 191-215). Oxford: Oxford University Press.

119. Williams, R. C. (2011). The Ninth Amendment as a Rule of Construction. Columbia Law Review, 111, 498-573.

120.Ziemele, I., De Gaetano, V., Laffranque. J. y Keller, H. (21 October 2013). Dissenting Opinion. En European Court of Human Rights. Case Janowiec and others vs. Russia. Application n. ${ }^{\circ 5} 55508 / 07$ and 29520/09. 